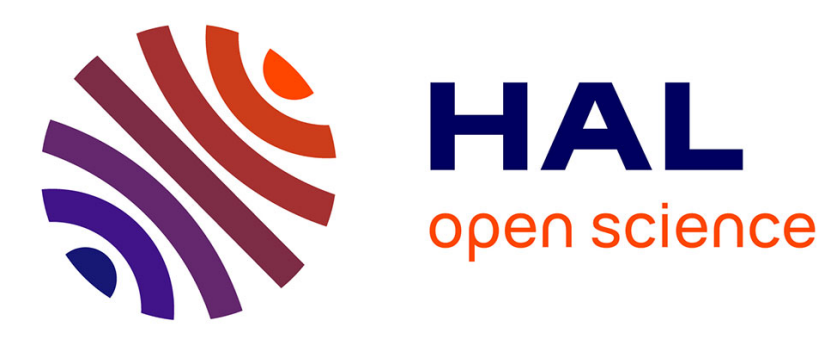

\title{
Study of screen-printed PZT cantilevers both self-actuated and self-read-out
}

Riadh Lakhmi, Hélène Debéda, Mario Maglione, Isabelle Dufour, Claude

Lucat

\section{- To cite this version:}

Riadh Lakhmi, Hélène Debéda, Mario Maglione, Isabelle Dufour, Claude Lucat. Study of screenprinted PZT cantilevers both self-actuated and self-read-out. International Journal of Applied Ceramics Technology, 2014, 11 (2), pp.311-320. 10.1111/ijac.12006 . hal-00725671

\section{HAL Id: hal-00725671 \\ https://hal.science/hal-00725671}

Submitted on 13 Nov 2014

HAL is a multi-disciplinary open access archive for the deposit and dissemination of scientific research documents, whether they are published or not. The documents may come from teaching and research institutions in France or abroad, or from public or private research centers.
L'archive ouverte pluridisciplinaire $\mathbf{H A L}$, est destinée au dépôt et à la diffusion de documents scientifiques de niveau recherche, publiés ou non, émanant des établissements d'enseignement et de recherche français ou étrangers, des laboratoires publics ou privés. 


\title{
Study of screen-printed PZT cantilevers both self-actuated and self-read-out
}

\author{
Riadh LAKHMI $^{(1)}$, Hélène DEBEDA ${ }^{(1)}(*)$, Mario MAGLIONE ${ }^{(2)}$, Isabelle DUFOUR ${ }^{(1)}$, Claude \\ LUCAT $^{(1)}$ \\ (1) Univ. Bordeaux, IMS, UMR 5218, F-33400 Talence, France. \\ (2) CNRS, ICMCB, UPR 9048, F-33600 Pessac, France. \\ *Email: helene.debeda@ims-bordeaux.fr
}

\begin{abstract}
Usually, resonating cantilevers come from silicon technology and are activated with pure bending mode. In this work, we suggest to combine high sensitive cantilever structure with both self-actuated and self-read-out piezoelectric thick-film for high electrical-mechanical coupling. This cantilever is realized through screen-printing deposition associated with a sacrificial layer. Itis composed of a PZT layer between two gold electrodes.
\end{abstract}

Optimum performances of piezoelectric ceramics generally imply the use of mechanical pressure and very high sintering temperature which are not compatible with the screen-printing process. Addition of eutectic composition $\mathrm{Li}_{2} \mathrm{CO}_{3}-\mathrm{Bi}_{2} \mathrm{O}_{3}-\mathrm{CuO}$ or borosilicate glass-frit to PZT powder and application of isostatic pressure improves the sintering at a given temperature. Firing temperature of $850^{\circ} \mathrm{C}, 900^{\circ} \mathrm{C}$ and $950^{\circ} \mathrm{C}$ are tested. Microstructural, electrical and mechanical characterizations are achieved. In addition to the bending mode, the in-plane 31longitudinal vibration mode and the out-of-plane 33-thickness resonance mode are revealed. Correlations between experimental results and modeling of the different vibration modes are established. The piezoelectric parameters of PZT cantilevers approach those of ceramics. Quality factors between 300 and 400 associated to the unusual 31-longitudinal mode make screen-printed PZT cantilevers good candidates for detection in liquid and gaseous media. 
Index Terms - cantilever, integrated actuation, integrated read-out, PZT, sintering, in-plane vibrations, chemical detection, liquid media, gaseous media.

\section{INTRODUCTION}

As other devices,microcantilever-based silicon ones are commonly used for chemical sensor applications, since their relatively simple structure allows high sensitivity to the environment [1-6]. In the latter case, the actuation part (electrothermal, electromagnetic, piezoelectric or electrostatic) and the integrated read-out (piezoresistive, piezoelectric...) are included in most of the microcantilever devices developed for species detection in gaseous or liquid media. The integration of those actuation and read-out parts into microcantilever devices enables to get rid of most of the external equipment to perform the detection and follow the current tendency to head towards so-called labs-on-a-chip.

Measurement can be achieved with static or various dynamic modes [7]. Assuming that piezoelectric materials can be used for both actuation and detection, one may consider that they are suitable for simplified and low-cost devices [8-10]. The electromechanical properties of mass-sensors made by screen-printing pure PZT layers on silicon microcantilevers show the influence of the porosity of $\mathrm{PZT}$ structures fired at $800^{\circ} \mathrm{C}$ [11]. Higher sintering temperatures $\left(1200^{\circ} \mathrm{C}-1300^{\circ} \mathrm{C}\right)$ leading to higher densification of pure PZT would confer high actuating force or sensitivity to sensor/actuator devices. To obtain equivalent electromechanical properties using the screen-printing process $\left(\mathrm{T}_{\text {firing }}<1100^{\circ} \mathrm{C}\right.$ ), addition of sintering aids is recommended for PZT densification at lower firing temperature.

A new type of PZT-based cantilevers containing $7 \mathrm{wt} \%$ borosilicate glass-frit, fired at low temperature $\left(850^{\circ} \mathrm{C}\right)$ has been successfully processed [12-13]. This fabrication combines screenprinting process and $\mathrm{SrCO}_{3}$ sacrificial layer method set-up in our laboratory. From these results, it is expected that the optimization of powder composition (nature and concentration of sintering aid) and firing conditions would improve the piezoelectric performances of screen-printed PZT cantilevers. On 
this way, Corker et al. [14] show that with low eutectic concentration $\left(3 \mathrm{wt} \% \mathrm{PbO}-\mathrm{Cu}_{2} \mathrm{O}\right)$, $\mathrm{PZT}$ ceramics fired at $900^{\circ} \mathrm{C}$ exhibit good piezoelectric properties similar to thoseobtained with $1.06 \mathrm{wt} \%$ $\mathrm{Li}_{2} \mathrm{CO}_{3}-\mathrm{Bi}_{2} \mathrm{O}_{3}-\mathrm{CuO}(\mathrm{LBCu})$ eutectic for ceramics fired at $880^{\circ} \mathrm{C}$ [15]. Other studies using 2$3 \mathrm{wt} \% \mathrm{LBCu}$ eutectic phase for the fabrication of ceramics and screen-printed thick films on $\mathrm{Al}_{2} \mathrm{O}_{3}$ substrates, confirm that good piezoelectric behavior is observed for samples fired at $900^{\circ} \mathrm{C}-950^{\circ} \mathrm{C}$ [16]. These results show the potentialities of $\mathrm{LBCu}$ eutectic for the fabrication of PZT-based layer. Moreover, it is noticed that thick-films directly screen-printed on the substrate do not favor the 31 inplane mode, conversely to PZT cantilever structure [17].

In this work, we propose the realization of PZT cantilevers with improved piezoelectric properties, using the association of the sacrificial layer to the standard screen-printing technology. SEM characterizations and electromechanical properties of cantilevers prepared from a mixture of a PZT powder with $3 \mathrm{wt} \% \mathrm{LBCu}$ or reduced concentration of borosilicate glass-frit (5wt\%), are investigated for different sintering temperatures $\left(850^{\circ} \mathrm{C}, 900^{\circ} \mathrm{C}\right.$ and $\left.950^{\circ} \mathrm{C}\right)$. Correlations between experimental results and modeling of the different vibrations modes are studied.

\section{DESIGN AND FABRICATION OF SCREEN PRINTED CANTILEVERS}

The simple design of PZT cantilevers used for this study is shown in figure 1. Thanks to the combination of the standard screen-printing technology with a sacrificial layer process, free-standing piezoelectric cantilevers are fabricated and released from the alumina substrate.

This multi-layered component is achieved by deposition of successive layers dried or polymerized $20 \mathrm{~min}$ at $120^{\circ} \mathrm{C}$ after each printing step (figure 2): (a) PZT pad, (b) sacrificial layer, (c) bottom electrode, (d) PZT cantilever, (e) top electrode. Once all the layers are deposited and dried, the samples are isostatically pressed $1 \mathrm{~min}$ at $1 \mathrm{kbar}$ to improve the densification [18]. The samples are then co-fired $2 \mathrm{~h}$ at $850^{\circ} \mathrm{C}, 900^{\circ} \mathrm{C}$ and $950^{\circ} \mathrm{C}$ with an heating rate of $20^{\circ} \mathrm{C} / \mathrm{min}$ and a cooling rate of 
$20^{\circ} \mathrm{C} / \mathrm{min}$. Finally, the removal of the sacrificial layer is performed in a diluted acidic solution (figure 2.f) and thus allows free movement of one extremity of the two-face electroded cantilever while the other one is clamped on the substrate via the pad. The decomposition of $\mathrm{SrCO}_{3}$ into $\mathrm{SrO}$ under controlled air atmosphere, taking place at a temperature around $850^{\circ} \mathrm{C}$, will not have any effect on the final device properties. Yet, it will affect the removal of the sacrificial layer since, contrary to $\mathrm{SrCO}_{3}, \mathrm{SrO}$ is not soluble in acidic solutions. The introduction of $\mathrm{CO}_{2}$ in the firing atmosphere would prevent the decomposition of $\mathrm{SrCO}_{3}$ and thus the $\mathrm{SrO}$ formation.

This cantilever is self-actuated thanks to the simple structure PZT beam sandwiched between symmetrical electrodes, also used at the same time to perform the signal transduction.

Two piezoelectric inks based on PZT powder (Pz26 from Ferroperm) are prepared by adding different metal oxide sintering aids. Each ink contains $3 \mathrm{wt} \% \mathrm{LBCu}\left(25 \mathrm{wt} \% \mathrm{Li}_{2} \mathrm{CO}_{3}, 40 \mathrm{wt} \% \mathrm{Bi}_{2} \mathrm{O}_{3}\right.$, $35 \mathrm{wt} \% \mathrm{CuO})$ or $5 \mathrm{wt} \%$ borosilicate glass-frit $\left(\mathrm{PbO}, \mathrm{B}_{2} \mathrm{O}_{3}, \mathrm{SiO}_{2}\right)$. After drying, the piezoelectric powders are mixed with an organic binder (ESL400 from Electro-Science Laboratories) and homogenized between two rotating plates to form a PZT paste with a suitable viscosity and rheology for the subsequent screen-printing process. The sacrificial layer paste is composed of $\mathrm{SrCO}_{3}$ dispersed in an epoxy binder CV59 from Electro-Science Laboratories. Concerning the bottom and top electrodes, commercial gold paste ESL8836 from Electro-Science Laboratories is used. For the two compositions of fired PZT cantilevers, the dimensions used in this study are for the length $L_{p}=8 \mathrm{~mm}$, width $b_{p}=2 \mathrm{~mm}$ and thickness $h_{p} \sim 105 \mu \mathrm{m}$ (figure 3). The symmetrical electrodes (thickness $h_{A u} \sim 7 \mu \mathrm{m}$ ) have a slightly smaller area than those of PZT beam in order to prevent short-circuits. 


\section{CHARACTERIZATION}

\section{A. Microstructural characterization}

Porosity plays an important role in piezoelectric ceramic. Indeed, a high porosity will have a detrimental effect on the piezoelectric properties of the ceramic since the pores act like small capacitors decreasing the efficiency of the electric field. Therefore, according to the firing conditions and the sintering aid addition, a control of the samples' porosities is required. The porosity has been evaluated thanks to SEM images by grey level analysis on different parts of the cantilever. Then, the estimated porosity is a mean value of the porosities observed.

SEM analyses of samples containing $5 \mathrm{wt} \%$ glass-frit and fired $15 \mathrm{~min}$ at $850^{\circ} \mathrm{C}$ show a porous microstructure with grain dimensions and agglomerates from a few hundreds of nm to about $10 \mu \mathrm{m}$, corresponding roughly to the initial PZT grain sizes and/or agglomerates (figure 4). Moreover, the sample exhibits a very high porosity estimated at $45 \%$ with macroporosities reaching $10 \mu \mathrm{m}$ diameter. The PZT layer is composed of grains having no cohesion giving rise to poor mechanical properties and stability. These preliminary results explain the choice of sintering time of $2 \mathrm{~h}$ at higher temperature to improve the densification of the samples.

Figure 5 shows the SEM analyses of the samples fired at $850^{\circ} \mathrm{C}, 900^{\circ} \mathrm{C}$ and $950^{\circ} \mathrm{C}$ for $(\mathrm{a}-\mathrm{c}) 5 \mathrm{wt} \%$ borosilicate glass-frit and (a'-c') $3 \mathrm{wt} \% \mathrm{LBCu}$ respectively. Concerning the $5 \mathrm{wt} \%$ glass-frit samples, it can be noticed that rising the sintering time from fifteen minutes to two hours improves the compacity of the PZT layer up to $70 \%$. Increasing more the sintering temperature leads to lower porosity ( $25 \%)$ for samples fired at $900^{\circ} \mathrm{C}$ and $\sim 20 \%$ for those fired at $950^{\circ} \mathrm{C}$.

Concerning the $3 \mathrm{wt} \% \mathrm{LBCu}$ samples fired at $850^{\circ} \mathrm{C}$ for two hours high porosity $(\sim 45 \%)$ is observed. As well, sintering at $900^{\circ} \mathrm{C}$ and $950^{\circ} \mathrm{C}$ decreases the porosity of the PZT layer to estimated values $\sim 35 \%$ and $\sim 25 \%$ respectively. 
Castaing microprobe analyses of PZT cantilevers shows low diffusion, into PZT layer, of SrO (figure 6). This strontium oxide is formed during the decarbonation of sacrificial layer during the firing process, starting from $850^{\circ} \mathrm{C}$ under air atmosphere.

\section{B. Electrical characterization}

Prior to piezoelectric properties studies, the PZT cantilevers are poled under dry helium atmosphere to avoid any conduction phenomenon between the electrodes leading to sample's breakdown. Therefore, a vacuum of 0.1 mbar is achieved before the introduction of helium, chosen for its good thermal conduction properties enabling better temperature homogenization inside the poling chamber. This poling is performed by applying an electric field of $5 \mathrm{kV} \cdot \mathrm{mm}^{-1}$ between the electrodes for $15 \mathrm{~min}$ at $280^{\circ} \mathrm{C}$, just below the measured Curie temperature $\left(\mathrm{T}_{\mathrm{C}} \# 284^{\circ} \mathrm{C}\right)$. It is worth noticing that the leakage current is controlled to make sure that it doesn't exceed $20 \mu \mathrm{A}$. Then, the temperature is lowered to room temperature before turning off the electric field.

The ferroelectric hysteresis loop is obtained at room temperature thanks to a Sawyer-Tower circuit for samples fired at $900^{\circ} \mathrm{C}$ for $2 \mathrm{~h}$ (figure 7). The measured coercive field $\mathrm{E}_{\mathrm{c}}=2.6 \mathrm{kV} / \mathrm{mm}$ remains lower than the electric field $\mathrm{E}_{\mathrm{p}}=5 \mathrm{kV} \cdot \mathrm{mm}^{-1}$ used to pole the samples. Compared to the remanent polarization of PZT ceramics $\left(30<\mathrm{P}_{\mathrm{r}}\left(\mu \mathrm{C} . \mathrm{cm}^{-2}\right)<50\right)$, those observed for the screen-printed cantilevers $\mathrm{P}_{\mathrm{r}}=2.2 \mu \mathrm{C} . \mathrm{cm}^{-}$ ${ }^{2}$ are relatively low. This may be explained by the high porosity remaining in PZT thick-films, the low diffusion of $\mathrm{SrO}$ at the electrode/PZT interface, etc.

The vibration spectrum of PZT cantilevers is recorded with an impedancemeter HP4194A. The first resonance peaks are observed for resonant frequencies around $75 \mathrm{kHz}, 220 \mathrm{kHz}$ and $370 \mathrm{kHz}$ (figure 8). From those peaks, corresponding to in-plane 31-longitudinal vibration modes, information on the quality factor $Q$ and piezoelectric characteristics like $\mathrm{d}_{31}$ can be extracted. 
At higher frequencies (around 10MHz), another resonance peak corresponding to out-of-plane 33thickness vibration mode is observed (figure 9).

The fabrication and poling processes have been validated on PZT-cantilevers whose measured first in-plane 31-longitudinal and first out-of-plane 33-thickness modes are respectively within the range $65-75 \mathrm{kHz}$ and $8-10 \mathrm{MHz}$. Indeed, quite reproducible results are obtained, the differences between the samples being mostly due to thickness variations.

For the in-plane modes and the out-of-plane ones, the quality factor has been calculated from the admittance spectra with $Q=\frac{f_{r}}{\Delta f}(\Delta f$ taken at $-3 \mathrm{~dB})$ (table 1). Piezoelectric coefficients $d_{31}$, dielectric constant $K_{33}^{T}$ and dielectric dissipation factor $(\tan \delta)$ are respectively extracted from admittance spectra and capacitance $\left(C_{p}\right) / \tan \delta$ spectra (figure 10) of the PZT cantilevers containing $5 \mathrm{wt} \%$ borosilicate glass-frit and $3 \mathrm{wt} \% \mathrm{LBCu}$ composition fired at $850^{\circ} \mathrm{C}, 900^{\circ} \mathrm{C}$ and $950^{\circ} \mathrm{C}$ (table 1) [19]. $\mathrm{K}^{\mathrm{T}}$ is defined as the ratio of the material's permittivity to the permittivity of free space while $\tan \delta$ is defined as the ratio of power dissipated by the ceramic on the active power. In a previous study [12], it has been pointed out that PZT layers containing $7 \mathrm{wt} \%$ of the same borosilicate glass-frit but fired $15 \mathrm{~min}$ at $850^{\circ} \mathrm{C}$ exhibited $Q$ values around 300 and 20 respectively for the in-plane longitudinal modes and the out-of-plane thickness mode, with a coefficient $d_{31}=-20 \mathrm{pC} \cdot \mathrm{N}^{-1}$.

For our samples, $Q$ values ranging from 240 to 770 for in-plane longitudinal modes and from 20 to 40 for the out-of-plane thickness mode are obtained. The lower $Q$ values of out-of-plane thickness mode could be explained by the fact that for this type of resonance, the waves move through the sample's thickness whose relative roughness (5\%) is not negligible. Moreover, this resonance is close to the electrical resonance of the sample coupling to the electrical connection of the impedance-meter which also affects the resonance peak. Results related to $Q$ values are comparable to those obtained for samples fired $15 \mathrm{~min}$ at $850^{\circ} \mathrm{C}$ and even better in some cases (Table 1). Actually, the quality factor depends not only on sintering but also on poling conditions and remanent polarization of the poled 
sample. Therefore, the obtained quality factors cannot be directly linked to the sintering temperature even if slightly better quality factors are obtained for samples fired $2 \mathrm{~h}$ at $900^{\circ} \mathrm{C}$.

The dielectric constant is an important property for a piezoelectric material since it is related to the capacity of the electroded piezoelectric material to store charge under a given electric field; so as the loss tangent which quantifies its inherent dissipation of electrical energy. A high porosity results in a poor effective dielectric constant $K_{33}^{T}$ and a reduced efficiency of the electric field which is, then, mainly applied on the porosities. For the poled samples, dielectric constant goes from 250 to 400 . Conversely, the observed porosity has a positive impact on the dielectric dissipation values which remains quite low ( 0.5 to $0.9 \%)$ for all the used firing cycles.

The piezoelectric constant $d_{31}$ is the ratio between the mechanical strain produced by converse piezoelectric effect and the applied electric field. In case of actuation applications, where a high electromechanical coupling is needed, the $d_{31}$ value is of high interest. Compared to samples fired $15 \mathrm{~min}$ at $850^{\circ} \mathrm{C}$, improved values $80 \mathrm{pC} / \mathrm{N}<-d_{31}<100 \mathrm{pC} / \mathrm{N}$ are obtained for $850<T\left({ }^{\circ} \mathrm{C}\right)<950$. These best mechanical and piezoelectric properties observed for samples fired at $900^{\circ} \mathrm{C}$ confirm the results of D.L. Corker [14] and X.X. Wang [15] on PZT ceramics presenting improved electromechanical properties at an optimal low firing temperature, related to the nature and the concentration of sintering aid. Indeed, X.X. Wang et al [15] observed on PZT ceramics a maximum value for Kp (and thus piezoelectric coefficient $\mathrm{d} 31$ ) at $880^{\circ} \mathrm{C}$ with the same $\mathrm{LBCu}$ sintering aids, though the dielectric constant is continuously decreasing with sintering temperature. It is worth noticing that in their case the compacity is well higher than $95 \%$. In the same way, D.L. Corker et al [14] have shown optimum piezoelectric properties at given sintering aid concentration $3<\mathrm{wt}(\%)<7$ at temperatures $800<\mathrm{T}\left({ }^{\circ} \mathrm{C}\right)<850$. In their case, the variations of tangdelta and piezoelectric properties are not linear with density. Moreover, the slight decrease of piezoelectric properties and increase of dielectric losses 
may result from the low diffusion of $\mathrm{SrO}$ at the electrode/PZT interface at increasing sintering temperature.

For samples containing borosilicate glass-frit and fired at $850^{\circ} \mathrm{C}$ for two hours, tested samples electrically broke down. Therefore, a higher sintering time (13h) has been tried and the influence of sintering time has been evaluated for samples with borosilicate glass-frit and fired at $850^{\circ} \mathrm{C}$ and $900^{\circ} \mathrm{C}$. Results are shown in table 2 . For both sintering temperatures, the effect of the sintering time on the piezoelectric and dielectric properties is positive since the samples fired at $850^{\circ} \mathrm{C}$ for $13 \mathrm{~h}$ can be poled and exhibit good properties. Dielectric properties of the sample fired at $900^{\circ} \mathrm{C}$ for $13 \mathrm{~h}$ have also been improved. The piezoelectric constant $d_{31}$ is almost unchanged.

\section{Mechanical characterization}

Whatever the firing temperature and the sintering aid, electrical characterizations show different resonance peaks that we attributed to in-plane longitudinal vibrations and out-of-plane thickness vibrations. Mechanical analysis performed with a vibrometerPolytec MSA 500 confirms that the assumed resonance modes are the correct ones. Indeed, the vibrometer can be used in its "out-of-plane mode" to detect the cantilever movements along the $z$ axis or in its "in-plane mode" to detect movements in the $x$ and the $y$ axis.Moreover, it enables to highlight the classical bending mode whose electrical signature is not sufficient to be electrically detected in the case of our cantilevers. Electromechanical characterizations are performed on samples fired $2 \mathrm{~h}$ at $900^{\circ} \mathrm{C}$ with $\mathrm{LBCu}$ sintering aid.

\section{- Out-of-plane measurements}

First, the vibrometerPolytec MSA 500 is used with its out-of-plane detection mode based on the Doppler Effect analysis of a laser beam reflection onto the cantilever's surface. The analysis is 
performed for an actuation voltage of a few $\mathrm{mV}$. At low frequencies (figure 11), peaks corresponding to the bending transverse modes are detected.

Our cantilever structure is composed of one PZT layer between two gold electrodes as seen in figure 4. The well-known equation for the transverse bending resonant frequency in this case is [20]:

$\mathrm{f}_{\text {bend }}^{(\mathrm{n})}=\frac{\lambda_{\text {bend }}^{(\mathrm{n})}{ }^{2}}{2 \pi \mathrm{L}^{2}} \sqrt{\frac{\mathrm{E}_{\mathrm{p}} \mathrm{h}_{\mathrm{p}}{ }^{3}+\mathrm{E}_{\mathrm{Au}}\left(\left(\mathrm{h}_{\mathrm{p}}+2 \mathrm{~h}_{\mathrm{Au}}\right)^{3}-\mathrm{h}_{\mathrm{p}}{ }^{3}\right)}{12\left(\rho_{\mathrm{p}} \mathrm{h}_{\mathrm{p}}+2 \rho_{\mathrm{Au}} \mathrm{h}_{\mathrm{Au}}\right)}}$

Where $\mathrm{n}, \lambda^{(1)}{ }_{\text {bend }}=1.875, \lambda^{(2)}{ }_{\text {bend }}=4.694, \lambda^{(3)}{ }_{\text {bend }}=7.855, L, b, h, E, \rho$ are respectively the mode's order, the cantilever's length, width, thickness, Young's modulus, density. The indexes $p$ and $A u$ refer respectively to the PZT layer and the gold electrodes.

The first measured bending resonant frequency $\left(f^{(1)}\right.$ bend $)$ is located around $600 \mathrm{~Hz}$. At this frequency, the noise level is high and the peak resolution is not quite good. This is why we decided to focus on the second transverse bending mode whose related resonant frequency is $f^{(2)}$ bend $=3.757 \mathrm{kHz}$.

The frequency limit of the optical vibrometer is $2.5 \mathrm{MHz}$. Therefore, the thickness mode could not be mechanically detected. For this mode the equation of the resonant frequency is [20]:

$f_{33}^{(n)}=\frac{\lambda_{33}^{(n)}}{2 \pi} \sqrt{\frac{\frac{E_{p} E_{A u}}{2 E_{p} h_{A u}+E_{A u} h_{p}}}{\rho_{p} h_{p}+2 \rho_{A u} h_{A u}}}$

where $\lambda^{(n)}{ }_{33}=n \pi$.

\section{- In-plane measurements}

To analyze the in-plane vibrations of the cantilever, the vibrometerPolytec MSA 500 is used with its in-plane detection mode. In this case, the frequency spectrum is obtained by stroboscopic effect.The analysis is performed for an actuation voltage of $9 \mathrm{~V}$. Peaks are detected around $75 \mathrm{kHz}$ and $220 \mathrm{kHz}$ (figures 12 and 13) corresponding respectively to the first and the second in-plane longitudinal modes 
observed with the impedancemeter. In order to verify that the observed modes correspond to in-plane 31-longitudinal modes, that's to say vibrations along the $\mathrm{x}$ axis, the displacement magnitudes on the 3 axis directions were compared.. For the in-plane mode observed at $75 \mathrm{kHz}$, peaks' amplitudes of 800 $\mathrm{nm}, 50 \mathrm{~nm}$ and a few hundreds of pm are measured respectively for $\mathrm{x}$ (figure $12 \mathrm{a}$ ), y (figure $12 \mathrm{~b}$ ) and $\mathrm{z}$ displacements. Besides, the same observation of a vibration mainly along the $x$ axis (figure 13) has been made for the resonance mode at $220 \mathrm{kHz}$. Displacements along y axis cannot be clearly determined because of the signal's noise. Thus, those measurements confirm that both peaks at 75 and $220 \mathrm{kHz}$ are related to in-plane 31-longitudinal modes whose resonant frequency for this multilayer geometry can be expressed by the following equation [20]:

$f_{31}^{(n)}=\frac{\lambda_{31}^{(n)}}{2 \pi L} \sqrt{\frac{h_{p} E_{p}+2 h_{A u} E_{A u}}{\rho_{p} h_{p}+2 \rho_{A u} h_{A u}}}$

where $\lambda_{31}^{(n)}=\frac{(2 n-1) \pi}{2}$

\section{- Resonant frequency agreement}

PZT thickness $(105 \mu \mathrm{m})$, Young's modulus $\left(\mathrm{E}_{\mathrm{Au}}=55 \mathrm{GPa}\right)$, density $\left(\rho_{\mathrm{Au}}=18500 \mathrm{~kg} / \mathrm{m}^{3}\right)$, thickness $(7 \mu \mathrm{m})$ of gold layers have been determined with vibrometer and profilometer measurements [21]. For samples fired 2 hours at $900^{\circ} \mathrm{C}$ with $\mathrm{LBCu}$ sintering aid, PZT density of $5500 \mathrm{~kg} / \mathrm{m}^{3}$ is estimated thanks to SEM photograph. Because of PZT's brittleness, Young's modulus cannot be measured directly with a monolayer PZT beam. Assuming that PZT is isotropic, the only unknown Young's modulus parameter is varied in order to obtain the best frequency fit with equation (3). The in-plane 31-longitudinal mode is the most reliable one for extraction of $E_{p} \sim 36 \pm 2 \mathrm{GPa}$ (mean value obtained on 20cantilevers), lower than the PZT ceramic's Young's modulus ( 70GPa). Indeed, the out-of-plane thickness and bending modes are both very sensitive to the layers'thicknesses because of the layers' roughness. Therefore, extraction of Young's modulus value is done thanks to fitting with 31- 
longitudinal mode equation (3). Then, errors made on the calculated out-of-plane bending and 33thickness resonant frequencies are evaluated using the extracted $E_{p}$ value. In the worst cases, measurements and calculated results for out-of-plane bending and 33-thickness modes revealed errors of respectively $23 \%$ and $12 \%$, as it can be seen on table 3 .

\section{CONCLUSION}

In this study, a self-actuated and self read-out PZT cantilever has been realized by screen-printing technique associated to a $\mathrm{SrCO}_{3}$ sacrificial layer. The microstructure revealed an evolution according to the sintering aid and the firing temperature used. Porosities of $20 \%$ and $25 \%$ are obtained respectively for samples with borosilicate glass-frit fired $2 \mathrm{~h}$ at $950^{\circ} \mathrm{C}$ and samples with $\mathrm{LBCu}$ fired $2 \mathrm{~h}$ at $950^{\circ} \mathrm{C}$.

From the electrical characterization, two resonance modes are identified: an in-plane longitudinal mode around $75 \mathrm{kHz}$ and an out-of-plane thickness vibration mode around $10 \mathrm{MHz}$. The quality factors (20 to 40), quite low for the out-of-plane thickness mode extracted from electrical measurement are much better for the in-plane vibration mode (300 to 400). Though the dielectric constant (250 to 400) is lower than those of ceramics, the piezoelectric coefficient $d_{31}\left(-75\right.$ to $\left.-100 \mathrm{pCN}^{-1}\right)$ approaches the values generally obtained with ceramics.

Mechanical characterizations performed on PZT cantilevers confirm the assumed vibration modes. Furthermore, analytical equations are used to predict the resonance behavior of the samples. 31longitudinal mode is used to extract Young's modulus value of PZT and the errors on the calculated out-of-plane resonant frequencies are evaluated with this extracted value. The errors on the out-ofplane bending and thickness modes reach respectively $20 \%$ and $12 \%$.

Moreover, the cantilevers are very attractive for species detection in gas and liquid media for many reasons, the high quality factor of the in-plane 31-longitudinal mode, the good mass sensitivity $\mathrm{S}_{\mathrm{m}}=$ - 
$2.3 \mathrm{~Hz} . \mu \mathrm{g}^{-1}$ or sensitivity to surfacic mass $S_{m_{\Sigma}}=-37 \mathrm{~Hz} \cdot \mathrm{mm}^{2} \cdot \mu \mathrm{g}^{-1}$, the low actuation power $(\mathrm{P}<10 \mu \mathrm{W})$, etc. 


\section{REFERENCES}

[1] A. Boisen, S. Dohn, S.S Keller, S. Schmid and M.Tenjer, Cantilever-like micromechanical sensors, Reports on Progress in Physics, Vol. 74, 036101 (30pp), 2011.

[2] M. Sepaniak, P. Datskos, N. Lavrik, C. Tipple, Microcantilever Transducers: A new Approach in Sensor Technology,AnalyticalChemistry, Vol. 74, 568-575, 2002.

[3] Goeders, K., Colton, J., Bottomley, L., Microcantilevers: Sensing Chemical Interactions via Mechanical Motion, Chemical Reviews, Vol. 108, 522-542, 2008.

[4] K. Länge, B.E. Rapp and M. Rapp, Surface acoustic wave biosensors: a review, Analytical and BioanalyticalChemistry,Vol. 391, pp. 1509-1519, 2008.

[5] T.M.A. Gronewold, Surface acoustic wave sensors in the bioanalytical field: Recent trends and challenges, analyticachimicaacta, Vol. 603, pp. 119-128, 2007.

[6] K. Arshak, E. Moore, G.M. Lyons, J. Harris and S. Clifford, A review of gas sensors employed in electronic nose applications, Sensor Review, Vol. 24, pp. 181-198, 2004.

[7] Q. Zhu, Microcantilever Sensors in Biological and Chemical Detections, Sensors \& Transducers Journal, Vol. 125, pp. $1-21,2011$.

[8] T. Yan, B.E. Jones, R.T. Rakowski, M.J. Tudor, S.P. Beeby, N.M. White, Design and fabrication of thick-film PZTmetallic triple beam resonators, Sensors and Actuators A: Physical, Vol. 115, pp. 401-407, 2004.

[9] R. Lou-Moeller,C. C. Hindrichsen,L. H. Thamdrup, T. Bove,E. Ringgaard,A. F. Pedersen, E. V. Thomsen, Screenprinted piezoceramic thick films for miniaturised devices,JElectroceram,Vol. 19, pp. 333-338, 2007.

[10] H. ZhihongWang,JianminMiao, Chee Wee Tan, Ting Xu, Fabrication of piezoelectric MEMS devices-from thin film to bulk PZT wafer,JElectroceram,Vol. 24, pp. 25-32, 2010.

[11] Jae Hong Park,HwanKim,Dae Sung Yoon, SooYooKwang,Jinhyung Lee, Tae Song Kim, Effects of the material properties on piezoelectric PZT thick film micro cantilevers as sensors and self actuators,J Electroceram,Vol. 25, pp. 1-10, 2010.

[12] C. Castille, Étude de MEMS piézoélectriques libérés et microstructurés par sérigraphie : application à la détection en milieu gazeux et en milieu liquide, PhDThesis, Université Bordeaux 1, (France), 2010.

[13] C. Lucat, P. Ginet, C. Castille, H. Debéda and F. Ménil,

Microsystems elements based on free-standing thick-films made with a new sacrificial layer process, Microelectronics Reliability, Vol. 48, pp. 872-875, 2008

[14] D.L. Corker, R.W. Whatmore, E. Ringgaard, W.W. Wolny, Liquid-phase sintering of PZT ceramics, Journal of the European Ceramic Society, Vol. 20, pp. 2039-2045, 2000.

[15]X.X. Wang, K. Murakami, O. Sugiyama and S. Kaneko, Piezoelectric properties, densification behavior and microstructural evolution of low temperature sintered PZT ceramics with sintering aids, Journal of the European Ceramic Society, Vol.21, pp. 1367-1371, 2001.

[16] L. Seveyrat, Elaboration et caractérisation de films épais piézoélectriques sérigraphiés sur alumine, aciers inoxydables et vitrocéramiques, PhDThesis, Université de Lyon, (France), 2002. 
[17] C. Castille,C. Lucat, P. Ginet, F. Ménil, M. Maglione, Free-standing piezoelectric thick-films for MEMS applications, IMAPS/ACerS 4th International Conference on Ceramic Interconnect and Ceramic Microsystems Technologies, Münich, April 21-24, 2008

[18] S. Gouverneur, C. Lucat, F. Ménil, J.L. Aucouturier, New densification process of thick films, IEEE Transactions, Comp. Hybrids Manuf. Technol.,Vol. 16, pp. 505-510, 1993.

[19] R. Lou-Moeller, C. Hindrichsen, « Screen-printed piezoceramic thickfilms forminiaturised devices », Journal of Electroceramics, Vol. 19, pp. 333-338,2007.

[20] R.D. Blevins, Flow induced vibration of bluff structures, PhD Thesis, California Institute of Technology (USA), 1973

[21] R. Lakhmi,H. Debéda,I. Dufour, C. Lucat, Determination of Young's Moduli for free-standing screen-printed thick film layers used in MEMS, 20th workshop on micromachining, micro mechanics and micro systems, Toulouse, 2009. 


\section{FIGURE CAPTIONS}

Figure 1. Design of the PZT cantilever

Figure 2. PZT cantilever fabrication: a) PZT pad, b) sacrificial layer, c) bottom layer d) PZT cantilever e) top electrode f) after firing and removal of the sacrificial layer

Figure 3. Screen-printed fired PZT cantilever

Figure 4. SEM analysis of a sample fired $15 \mathrm{~min}$ at $850^{\circ} \mathrm{C}$

Figure.5. SEM analysis of samples with $5 \mathrm{wt} \%$ borosilicate glass-frit fired $2 \mathrm{~h}$ at a) $850^{\circ} \mathrm{C}$, b) $900^{\circ} \mathrm{C}$, c) $950^{\circ} \mathrm{C}$ and with $3 \mathrm{wt} \% \mathrm{LBCu}$ fired $2 \mathrm{~h}$ at a') $\left.\left.850^{\circ} \mathrm{C}, \mathrm{b}^{\prime}\right) 900^{\circ} \mathrm{C}, \mathrm{c}^{\prime}\right) 950^{\circ} \mathrm{C}$.

Figure 6. Microprobe analysis of the PZT/electrode interface close to the sacrificial layer

Figure 7. Ferroelectric hysteresis loop at room temperature obtained thanks to a Sawyer-Tower circuit for samples fired for $2 \mathrm{~h}$ at $900^{\circ} \mathrm{C}$.

Figure 8. Electrical signature of the in-plane longitudinal vibration modes

Figure 9. Electrical signature of the out-of-plane thickness vibration mode

Figure 10. Capacity / Dielectric dissipation factorspectra of a cantilever

Figure 11. Mechanical spectrum of a sample in its bending mode

Figure 12.First in-plane longitudinal mode for vibrations along a) $x$ axis and b) $y$ axis.

Figure 13.Second in-plane longitudinal mode for vibrations along $x$ axis. 


\section{TABLES}

Table 1. Electro-mechanical properties of samples fired $2 \mathrm{~h}$

\begin{tabular}{|c|c|c|c|c|c|c|c|}
\hline & \multirow[b]{2}{*}{$\begin{array}{l}\mathrm{T}_{\text {firing }} \\
\left({ }^{\circ} \mathrm{C}\right)\end{array}$} & \multicolumn{3}{|c|}{ Quality factor $(Q)$} & \multirow[b]{2}{*}{$\begin{array}{c}\mathrm{K}_{33}^{\mathrm{T}} \\
\quad \text { at } \\
1 \mathrm{kHz})\end{array}$} & \multirow[b]{2}{*}{$\begin{array}{c}\tan (\delta) \\
\quad(\text { at } \\
1 \mathrm{kHz})\end{array}$} & \multirow[b]{2}{*}{$\begin{array}{c}-\mathrm{d}_{31} \\
(\mathrm{pC} / \mathrm{N})\end{array}$} \\
\hline & & $\begin{array}{c}\text { First } \\
31 \\
\text { mode }\end{array}$ & $\begin{array}{c}\text { Second } \\
31 \\
\text { mode }\end{array}$ & $\begin{array}{c}33 \\
\text { mode }\end{array}$ & & & \\
\hline \multirow{3}{*}{$\begin{array}{c}\text { Glass- } \\
\text { frit }\end{array}$} & 850 & - & - & - & - & - & - \\
\hline & 900 & 320 & 770 & 20 & 340 & 0.007 & 90 \\
\hline & 950 & 430 & 270 & 20 & 390 & 0.009 & 80 \\
\hline \multirow{3}{*}{$\mathbf{L B C u}$} & 850 & 240 & 320 & 20 & 330 & 0.007 & 100 \\
\hline & 900 & 330 & 370 & 40 & 340 & 0.006 & 100 \\
\hline & 950 & 330 & 340 & 30 & 270 & 0.009 & 80 \\
\hline
\end{tabular}


Table 2. Firing temperature time influence on the properties of samples containing borosilicate glassfrit

\begin{tabular}{|c|c|c|c|c|c|c|c|}
\hline \multirow{2}{*}{$\begin{array}{c}\mathrm{T}_{\text {firing }} \\
\left({ }^{\circ} \mathrm{C}\right)\end{array}$} & $\begin{array}{c}\text { Firing } \\
\text { time } \\
(\mathrm{h})\end{array}$ & $\begin{array}{c}\text { First } \\
31 \\
\text { mode }\end{array}$ & $\begin{array}{c}\text { Second } \\
31 \\
\text { mode }\end{array}$ & $\begin{array}{c}33 \\
\text { mode }\end{array}$ & $\mathrm{K}_{33}^{\mathrm{T}}$ & $\begin{array}{c}\tan (\delta) \\
(\text { at } \\
1 \mathrm{kHz})\end{array}$ & $\begin{array}{c}-\mathrm{d}_{31} \\
(\mathrm{pC} / \mathrm{N})\end{array}$ \\
\hline \multirow{2}{*}{$\mathbf{8 5 0}$} & 2 & - & - & - & - & - & - \\
\cline { 2 - 8 } & 13 & 220 & 220 & 20 & 310 & 0.006 & 90 \\
\hline \multirow{2}{*}{$\mathbf{9 0 0}$} & 2 & 320 & 770 & 20 & 340 & 0.006 & 90 \\
\cline { 2 - 8 } & 13 & 330 & 340 & 30 & 390 & 0.005 & 90 \\
\hline
\end{tabular}


Table 3. Comparison between experimental and calculated values for the flexural and thickness modes for the cantilevers $1,2,3(\mathrm{~L}=8 \mathrm{~mm} / \mathrm{w}=2 \mathrm{~mm} / \mathrm{t}=120 \mu \mathrm{m})$

\begin{tabular}{|l|c|c|c|c|c|c|}
\hline & $\begin{array}{c}\boldsymbol{f}_{(\mathbf{f})}^{\text {flex exp }} \\
(\boldsymbol{H z})\end{array}$ & $\begin{array}{c}\boldsymbol{f}_{\text {(2) }}^{\text {flex model }} \\
(\mathbf{H z})\end{array}$ & Error (\%) & $\begin{array}{c}\boldsymbol{f}_{33 \text { exp }} \\
(\mathbf{M H z})\end{array}$ & $\begin{array}{c}\boldsymbol{f}_{33 \text { model }} \\
(\mathbf{M H z})\end{array}$ & Error (\%) \\
\hline Cantilever 1 & 4135 & 4516 & $\mathbf{9 . 2}$ & 8.702 & 9.599 & $\mathbf{1 0 . 3}$ \\
\hline Cantilever 2 & 4073 & 4425 & $\mathbf{8 . 6}$ & 9.525 & 9.298 & $\mathbf{2 . 4}$ \\
\hline Cantilever 3 & 3757 & 4625 & $\mathbf{2 3 . 1}$ & 8.923 & 9.947 & $\mathbf{1 1 . 5}$ \\
\hline
\end{tabular}

